\title{
Special issue of the 12th International Symposium on Novel and Nanomaterials 2012
}

\author{
I. -S. Ahn • S. -H. Hong • W. -W. Kim • J. -S. Chang • \\ S. -J. Park
}

Published online: 11 May 2014

(C) Springer Science+Business Media Dordrecht 2014

The 12th International Symposium on Novel and Nano Materials 2012, ISNNM2012, was held in Istanbul, Turkey, from 26 to 30 August 2012. Unlike previous series of nanocomposite materials symposia, this symposium was focused on all nanomaterials research, for example Advanced Powder Metallurgy, Advanced Material Processing, Novel Functional Materials, Nanocomposites and Nanoporous materials, Energy and Nuclear Materials, Characterization and Modeling, Resources and Recycling, Rare Metals, and Mechanical Alloying and Mechanochemistry.

Approximately 190 participants from nine countries attended the symposium and 241 papers were presented-3 plenary lectures from Korea, Turkey, and Japan, 49 other oral presentations, and 170 poster presentations. After the reviewing process,

\section{I.-S. Ahn}

School of Nano and Advanced Materials Engineering, I-Cube Center, K-MEM R\&D Cluster, Gyeongsang National University, Jinju 660-701, Korea

e-mail: ahnspml@gnu.ac.kr

\section{S.-H. Hong}

Department of Material Science and Engineering, KAIST, 335 Gwahak-ro, Yuseong-gu, Daejeon 305-701, Korea

e-mail: shhong@kaist.ac.kr

\section{W.-W. Kim}

Advanced Nuclear Materials Department, Korea Atomic Energy Research Institute,

Daejeon 305-353, Korea

e-mail: wwkim@kaeri.re.kr

J.-S. Chang

Catalysis Center for Molecular Engineering (CCME), Korea Research Institute of Chemical,

Technology (KRICT), Yusung, Daejeon 305-600, Korea

e-mail: jschang@krict.re.kr 
26 papers were accepted for publication in this special volume of Research on Chemical Intermediates. The enthusiastic international participation and high quality of presentations is an indication of the interest in nano-composites, nanocatalysts, ultrafine polymers, nano-adsorbents, nano-characterization, etc., in fundamental research and applied engineering. All the main aspects of these materials were covered, including synthesis, mechanisms, microstructures, properties, and applications.

The symposium also provided the latest research results and a state-of-the-art overview of technology in this exciting and rapidly evolving field of novel and nano materials. In the oral sessions of the Symposium, research on Advanced Powder Metallurgy, Advanced Material Processing, Novel Functional Materials, Nanocomposites and Nanoporous materials, Energy and Nuclear Materials, Characterization and Modeling, Resources and Recycling, Rare Metals, and Mechanical Alloying and Mechanochemistry was reported. In the poster session of the Symposium, many papers on the properties and applications of a variety of nanomaterials, including metal alloys, carbon materials, ceramics, etc., were actively discussed.

We would like to thank the Local Organizing Committee and are also grateful for invaluable administrative support, both before and during the Symposium, by the High-Performance Nanocomposites Program (KAERI), the Korea Institute of Materials Science (KIMS), the University of Ulsan, the Nano Center for Fine Chemicals Fusion Technology (Inha University), the Korean Powder Metallurgy Institute (KPMI), and Istanbul Technical University (ITU). We would also like to acknowledge financial support from many industrial companies and from the Korean government agencies Ministry of Commerce, Industry and Energy (MOCIE) and the Asian Office of Aerospace Research and Development (AOARD). Without their support, the Symposium would have been less successful.

\section{Organizing committee (ISNNM-2012)}

\section{Co-Editor}

\section{Professor Soo-Jin Park}

Committee members

Dr Jae-Pyoung Ahn, KIST

Professor Jung-Ho Ahn, Andong National University

Dr Kay Hyeok An, JMC

Dr Jong-San Chang, KRICT

Dr Yoo Dong Hahn, KIMS

Professor Soon-Jik Hong, Kongju National University

Dr Jin Soo Hwang, KRICT

Dr Young Kyu Hwang, KRICT

Professor Sung Hwa Jhung, Kyungpook National University

Professor Suk-Joong L. Kang, KAIST 
Professor Deug Joong Kim, SKK University

Professor Chun-Gon Kim, KAIST

Dr Byoung Kee Kim, KIMS

Professor Ji-Soon Kim, University of Ulsan

Professor Seok Kim, Pusan National University

Dr Whung Whoe Kim, KAERI

Professor Young Do Kim, Hanyang University

Professor Young-Uk Kwon, SKK University

Dr Kwang-Ryeol Lee, KIST

Professor Joung Man Park, Gyeongsang National University

Professor Soo-Jin Park, Inha University

Professor Won-Wook Park, Inje University

Dr Chang Kyu Rhee, KAERI

Dr Sang Hee Suh, CNMT

International advisory committee

Professor Guoxiu. Wang, University, Wollongong, Australia

Professor Zbigniew H. Stachurski, The Australian National University, Australia

Dr A. S. Kalinichenko, BNTU, Belarus

Dr Igar Pobal, Plasma Research Institute, Belarus

Dr Jiri Cejka, J. Herrovsky Institute of Czech, Czech Republic

Dr Gerard Ferey Institute Lavoisier (UMB CNRS 8180), France

Professor Noorul Hassan Khan, CSIR, India

Dr Raksh Vir Jasra, CMCRI, India

Professor Salvatore, Coluccia University of Torino, Italy

Professor Mazakasu Anpo, Osaka Prefecture University, Japan

Dr S. B. Halligudi, National Chemical laboratory, India

Professor Susumi Kitagawa, Kyoto University, Japan

Professor Masaya Matsuoka, Osaka Prefecture University, Japan

Dr Tsuyoshi Nakajima, Aichi Institute of Technology, Japan

Dr Ajayan Vinu, National Institute for Materials Science, Japan

Professor T. Yamamoto, University of Tokyo, Japan

Dr Tadeusz Pieczonka, AGH University of Sci and Tech., Poland

Professor Bogumil Weglinski, Wroclaw University. of Tech. Poland

Professor Yury. A. Kotov, Institute of Electrophysics, Russia

Professor Anna Brainina, Ural State University. of Economy, Russia

Dr Vicente Cortes Corberan, Inst. De Catalisisy Petroleoquimica, CSIC, Spain

Professor Simon M. Humphrey, St. John's College Cambridge, United Kingdom

Professor Paul T. Wood, Chemical Laboratory University, United Kingdom

Professor Marian Mazurkiewicz, Missouri-Rola University, USA

Professor Steve Choi, UIC, USA

Professor David Dunand, Northwestern University, USA 